\title{
Outpatient pulmonary rehabilitation in patients with chronic obstructive pulmonary disease
}

\author{
Shahin Barakat' \\ Germain Michele ${ }^{2}$ \\ Pastene George ${ }^{3}$ \\ Viallet Nicole ${ }^{4}$ \\ Annat Guy
}

'Master of (experimental physiopathology) and doctoral student of physiopathology; ${ }^{2} \mathrm{Chef}$ of the service of EFR, Hospital of the Croix-Rousse at Lyon, France; ${ }^{3}$ Hospital of Croix-Rousse at Lyon, France; ${ }^{5}$ Service of EFR, Hospital of the Croix Rousse at Lyon, France; ${ }^{5}$ UFR Médecine Lyon Grange-Blanche Université Claude Bernard Lyon I, INSERM ESPRI ERI 22, Lyon, France

Correspondence: Shahin Barakat 6.chemin du grand boìs 69120 vaulx en velin France

Tel +33 $627923058 /+33426656 / 26$

Fax +3347216875

Email barakat.shahin@free.fr/ shahin.barakat@yahoo.fr
Objective: To evaluate an entirely outpatient-based program of pulmonary rehabilitation in patients with chronic obstructive pulmonary disease COPD, using St.George's Respiratory questionnaire (SGRQ), the 6-minutes walking test (6-MWT) and BODE index as the primary outcome measures.

Methods: A prospective, parallel-group controlled study of an outpatient rehabilitation program in 80 patients with COPD (67 men and 13 women; mean age $64.8 \pm 10.6$ years; $\mathrm{FEV}_{1}, 42.8 \%$ $\pm 7.6 \%$ of the predicted value. The active group $(n=40)$ took part in a 14 -week rehabilitation program [ $3 \mathrm{~h} / \mathrm{wk}, 1.5 \mathrm{~h}$ of education and exercise and $1.5 \mathrm{~h}$ of cycling]. The control group $(n=40)$ was reviewed routinely as medical outpatients. The following evaluations were carried out at study entry and after14 weeks: (1) pulmonary function studies; (2) 6-minutes walking test 6MWT; (3) quality of life; and (4) BODE index.

Results: The following patients completed the study: 35 patients $(87.5 \%)$ from the active group (mean age, $63.7 \pm 11.9$ years; mean forced expiratory volume in one second $\left(\mathrm{FEV}_{1}\right)$, $41.9 \pm 2.6 \%$ of the predicted value); and 36 patients ( $88 \%$ ) from the control group (mean age, $65.9 \pm 10.3$ years; mean $\mathrm{FEV}_{1}, 43.33 \pm 3.6 \%$ of the predicted value). We found no changes in pulmonary function parameters in the active group and the control one at 14 weeks. On the other hand, there were significant changes within the components of the SGRQ (12.3 for the score total) for the patients of the active group but not for the patients of the control one (only 1.5 for the score total), we observed also a significant increase in the distance of the 6-MWT in the patients of the active group but not for the patients of the control one, and finally a decrease of two points (from 6 to 4 ) was noted in the score of the active group's BODE index without any change in the control group's one.

Conclusion: An outpatient-based of 14-week rehabilitation program significantly improved the quality of life and exercise tolerance without any change in the pulmonary function in patients with moderate COPD, and there was also a large decrease in the risk of death in rehabilitated patients as measured using the BODE index.

Keywords: COPD, quality of life, pulmonary rehabilitation, 6-minute walking test, BODE index

\section{Introduction}

Chronic obstructive pulmonary disease (COPD), which is defined as a disease state characterized by progressive airflow limitation that is not fully reversible, and is associated with an abnormal inflammatory response of lungs to noxious particles or gases, primarily cigarette smoke (Celli et al 2004; Global Initiative for Chronic Obstructive Lung Disease 2005), is a highly prevalent disease that has a large impact on quality of life for patients and their families and kills millions of people worldwide (Global Initiative for Chronic Obstructive Lung Disease 2005; Strong et al 2005). In 2004, the American Thoracic Society/European Respiratory Society guidelines introduced in the definition the concept that, although COPD affects the lungs, it also produces significant systemic consequences (Celli et al 2004). 
Patients with COPD are markedly inactive in daily life and are often characterized by a downward spiral of symptom-induced inactivity, leading to deconditioning and muscle weakness (Rennard et al 2003), which results in spending less and less time walking and standing compared with sedentary healthy elderly subjects (Pitta et al 2005).

Systemic effects of COPD involve respiratory and skeletal muscles ( $\mathrm{Sin}$ et al 2004; Agusti et al 2005; MacNee et al 2005; Man et al 2005; Oudijk et al 2005; Tapson et al 2005; Wouters et al 2005; Yasuda et al 2005). In patients with COPD, the functional impairment of the diaphragm is associated with loss of myosin heavy chain and elevated level of ubiquitin-conjugated proteins, suggesting accelerated muscle protein degradation. In addition, the remaining contractile proteins in these fibres are dysfunctional, and the calcium sensitivity of force generation is reduced. These abnormalities could all contribute to muscle weakness, particularly at sub-maximal activation, even in patients with mild to moderate COPD (Ottenheijm et al 2005).

Abdominal muscle strength in the presence of quadriceps weakness is preserved in stable outpatients with COPD, suggesting that disuse and consequent deconditioning contribute to the development of quadriceps muscle weakness, and/or that activities like postural one protect the abdominal muscles from systemic myopathic process (Man et al 2005).

Skeletal muscle dysfunction has now been widely accepted in COPD, and has been reviewed in several excellent reviews (American Thoracic Society 1999; Debigare et al 2001; Laghi et al 2003). Skeletal muscle atrophy or weakness is clearly a negative prognostic factor (Decramer et al 1997; Decramer et al 1998; Marquis et al 2002) and requires appropriate action. The potential for at least partial reversibility of this dysfunction is believed to be an important determinant of the physiological gain achieved with pulmonary rehabilitation.

Pulmonary rehabilitation is now considered to be a mainstay of treatment for patients with chronic lung disease; it has been shown to result in many benefits, including improvement in exercise performance, reduction of dyspnoea, improvement in health- related quality of life, and reduction in health-care utilization (Ries et al 1995; American College of Chest Physicians 1997; American Thoracic Society 1999; Verrill et al 2005). Key elements include a multidisciplinary approach to care with a focus on the individual patients through education, exercise, and psychosocial interventions. Appropriate candidates for pulmonary rehabilitation are symptomatic patients with chronic lung disease who are aware of their disability and are motivated to participate actively in their health care. In other words, according to the Global Initiative for Chronic Lung Disease consensus statement on the management of COPD (Fabbri et al 2003), pulmonary rehabilitation should be considered for patients with a forced expiratory volume in one second $\left(\mathrm{FEV}_{1}\right)$ of $<80 \%$ of the predicted value.

\section{Objective}

This study aims to evaluate the effects of an outpatient program of physical exercise used especially for the lower limbs (quadriceps muscle) and with an ergo-metric-bicycle, this program was designed to improve the exercise capacity and the quality of life in patients with moderate to severe COPD, in addition to evaluate the effect of this program on the mortality rate in this group of patients using BODE index (Bartolome et al 2004).

\section{Materials and methods Patients}

Patients accepted in the study were known to the respiratory team at the hospital as having long-standing airway disease, classified as COPD, and were examined at an outpatient clinic by a respiratory specialist who discussed the study in the course of assessing their condition and progress. All had had their therapy optimized. Patients were assessed as to their ability to comply with the requirements of the program, specifically the time and travel commitments involved. Among our 80 patients, there were 62 smokers, among these smokers 43 had given up smoking one month before the beginning of the program, and the remaining 19 smokers were prepared to make an active effort to stop smoking during the proposed program, but non of them have absolutely quitted by the end of the program.

Contraindications to entry in to the study were unstable medical conditions, such as congestive cardiac failure, cor-pulmonale, malignancy, or cerebrovascular accident. We also excluded the patients with sleep apnea syndrome. None had previously taken part in the supervised respiratory rehabilitation program.

Patients were assessed using a standard 6-min walk, spirometry, plethismography, and each completed the SGRQ. All of these tests were supervised by a blinded observer who subsequently repeated this assessment before the study and at the end of the study ( 0 and 14 weeks). BODE index was also computed at the study entry and at the end of study for all patients. At the study entry, patients were randomized to either the rehabilitation program of 40 -sessions for a total period of 14 weeks or to routine outpatient attendance 
at 4-month intervals. Randomization was in blocks of 10 , using random numbers.

All patients were informed of the objectives and design of the study and gave their informed consent to participate in this rehabilitation program which was approved by our local institutional review board.

\section{Rehabilitation program}

The 14-week outpatient-based rehabilitation program involved three visits per week: a 30-min education and exercises visit and a 30-min session of cycling on an ergometric bicycle.

During the course of the program, patients underwent an initial medical assessment and then received information from a team composed of a physiotherapist, a respiratory specialist nurse, and a dietician.

We began with an intensity of 25 watts and we increased the intensity by 5 watts each week until reaching the intensity of 40 watts, at which time, the VO2 max was achieved for the patient. The aim after that was to reach the intensity of $80 \%$ of the VO 2 max of each patient.

\section{Physiotherapy}

The physiotherapist discussed breathing problems and emphasized exercise regime. At the 30-min exercise there was 5-min warm-up period, 10-min of aerobic activity and 15-min cool-down period. The aerobic activity included diagonal arm raises, arm abduction into elevation and reverse, and arm abduction, forward flexion, and reverse; and straight leg rises.

\section{Dietary assessment and advice}

Each patient's body mass index (BMI) and dietary history were assessed, and progress in the body weight change was assessed every week.

\section{Parameters studied}

\section{Spirometry}

A Pneumocheck(R) spirometer (ms medi-soft module 5500, USA) was used, and all procedures were carried out according to ATS guidelines (American Thoracic Society 1995). The parameters evaluated were: forced vital capacity (FVC), $\mathrm{FEV}_{1}$, the $\mathrm{FEV}_{1} / \mathrm{FVC}$ ratio, and we assessed the residual volume (RV) by plethysmography (medi-soft).

\section{Quality of life}

Patients were evaluated with the Saint George's Respiratory Questionnaire (SGRQ), which is specifically designed for respiratory disease (Jones et al 1992). A trained interviewer administered the questionnaire and if a patient failed to understand a question, the interviewer repeated it until the patient chose an alternative.

\section{Walking test}

Each patient was submitted to a 6-minute walking test (6MWT), conducted in a closed corridor of 30 meter. Each test was given twice, with a 10-15 minute interval between the two. During the test the patient was instructed to walk as fast as possible for six minutes and to decrease speed or interrupt the test if experiencing severe dyspnoea or any other limiting discomfort. The examiner gave patients verbal encouragement once per minute using standard motivational phrases intended to ensure that patients walked as fast as possible throughout the test. Heart rate, dyspnoea, and partial oxygen saturation were measured before and after each test. A trained investigator who did not have access to previous evaluations applied the test or information on the group the patient belonged to.

\section{Bode index}

It is a multidimensional index which includes four factors that predict the risk of death: the body mass index $B$, the degree of air flow obstruction $\mathrm{O}$, the functional dyspnoea $\mathrm{D}$, and exercise capacity $\mathrm{E}$ as assessed by the six-minutes walk test (Bartolome et al 2004).

\section{Computation of BODE index}

For each threshold value of $\mathrm{FEV}_{1}$, distance walked in six minutes, and score of the MMRC dyspnoea scale as shown in Table1, the patients received points ranging from 0 (lowest

Table I Variables and point values used for the computation of the body mass index, degree of airflow obstruction and dyspnoea, and exercise capacity (BODE) index

\begin{tabular}{lllll}
\hline Variable & \multicolumn{4}{l}{ Points on BODE index } \\
\hline & 0 & $\mathrm{I}$ & 2 & 3 \\
FEV $_{1} \%$ of predicted)** & $>$ or $=65$ & $50-64$ & $36-49$ & $<$ or $=35$ \\
$\begin{array}{l}\text { Distance walked } \\
\text { in } 6 \text { min }(\mathrm{m})\end{array}$ & $>$ or $=350$ & $250-349$ & $150-249$ & $<$ or $=149$ \\
MMRC dyspnea & & & & \\
Body mass index $^{\S \S}$ & $0-1$ & 2 & 3 & 4 \\
\hline
\end{tabular}

Notes: *The cutoff values for the assignment of points are shown for each variable; The total possible values range from 0 to 10 . FEV , donated forced expiratory volume in one second; **The FEV, categories are based on stages identified by the American Thoracic Society; ${ }^{\S}$ Scores on the modified Medical Research Council (MMRC) dyspnoea scale can range from 0 to 4 , with a score of 4 indicating that the patient is too breathless to leave the house or becomes breathless when dressing or undressing; ${ }^{\S}$ The values for body-mass index were 0 or I because of the inflection point in the inverse relation between survival and body mass index at a value of 21 . 
value) to 3 (maximal value). For body mass index, the values were 0 or 1 , because of the unique relation between body mass index and survival among COPD patients. The points for each variable were added, so that the BODE index ranged from 0 to 10 points, with higher scores indicating a greater risk of death.

\section{Statistical analysis}

To determine whether subjects altered their parameters of pulmonary function like $\left(\mathrm{FEV}_{1} / \mathrm{FVC}, \mathrm{FEV}_{1}\right.$, and RV) before the physical exercise program were compared with their respective values 14 weeks afterwards.

The scores of SGRQ were obtained before the program and 14 weeks later. All data are reported as means \pm standard deviation (S.D.) and $\mathrm{p}<0.05$ was accepted as indicating a significant change. Statistical analysis was performed using a statistical software program (SAS, version 8.2; SAS Institute).

An unpaired $t$-test was done of the difference between the baseline measurement and the measurement at 14 weeks, and $95 \%$ confidence intervals (CIs) were constructed for the difference between the mean changes in each of the two groups. In addition, paired $t$-tests were performed within each group to assess whether changes from baseline had occurred.

\section{Results}

Eighty patients who were believed to fulfil the criteria of the study were approached, and they agreed to provisional assessment and detailed discussion of the requirements of the study. Of these, 40 were randomized to the active group; 40 were randomized to the control group. Five patients in the active group were excluded from analysis (3 patients were not only COPD (association with sleep apnea syndrome $n=3$ ) and 2 patients were excluded because of their absence for 4 consecutive sessions, and 4 patients were also excluded from the control group ( 2 patients had a cardiac problem during the first month of the program and 2 patients had an association with sleep apnea syndrome) leaving 71 patients with COPD recruited to the study.

The mean $\mathrm{FEV}_{1}$ was $(41.9 \% \pm 2.6 \%)$ in the active group versus $(43.33 \% \pm 3.6 \%)$ in the control group; the mean FVC was $(86.1 \% \pm 17.8 \%)$ in the active group versus $(78.7 \% \pm 3.5)$ in the control group. There was no significant difference in sex distribution, age, or spirometry measures between the two groups (Table 2).

\section{Quality of life measures}

The SGRQ is a 76-weighted-item questionnaire, in which results are expressed for symptoms, activity, impacts on
Table 2 Patient characteristics

\begin{tabular}{lll}
\hline Characteristics & Active group & Control group \\
\hline Male/female gender, No. & $34 / 6$ & $33 / 7$ \\
Age, yr & $63.7 \pm(I 1.9)$ & $65.9 \pm(10.3)$ \\
BMI & $24.2 \pm(6.4)$ & $25.6 \pm(4.3)$ \\
FEV $_{1}, \%$ predicted & $41.9 \pm(2.6)$ & $43.33 \pm(3.6)$ \\
FVC, \% predicted & $86.1 \pm(17.8)$ & $78.7 \pm(3.5)$ \\
\hline
\end{tabular}

Notes: Data are presented as mean \pm SD unless otherwise indicated.

daily life, and an integrated total score. The groups were well matched for SGRQ scores and walking distances on study entry (Table 3).

The SGRQ integrated total scores for control group were $(58.5 \pm 3.7)$ at study entry and $(53.1 \pm 3.0)$ at 14 weeks (end of the study). For the control group, there were no significant differences over the 14-week study period in scores for symptoms, impacts on daily life, activity, or integrated total scores (Table 4).

The SGRQ integrate total scores for the active group were $(59.6 \pm 3.2)$ at the study entry $(n=35)$ which closely matched the scores in the control group. At 14 weeks, the mean SGRQ total score was $(47.3 \pm 2.6)$. This was significant different from baseline ( $\mathrm{p}<0.05$, paired $t$ - test) with a mean reduction of total scores of 12.8. The changes from baseline in SGRQ total score at 14 weeks were compared between the active and control groups: the mean difference was a reduction of 10.3 in favor of the active group $(\mathrm{p}<0.05)$.

A secondary analysis of the components of the total SGRQ, namely symptom score, activity score, and impact on daily living score revealed significant reductions in all three components in the active group (for each of them $p<0.05$ ), and that the change in total scores could not be attributed principally to a change in any one component.

\section{Walking distance}

The mean distances walked over $6 \mathrm{~min}$, supervised by a physiotherapist blinded to the subject randomization, are summarized in Table 5. The active group had a longer

Table 3 Baseline SGRQ scores and walking distances for active and control groups

\begin{tabular}{lll}
\hline Parameters & $\begin{array}{l}\text { Active group } \\
(\mathbf{n}=\mathbf{3 5})\end{array}$ & $\begin{array}{l}\text { Control group } \\
(\mathbf{n}=\mathbf{3 6})\end{array}$ \\
\hline Symptom score & $38.2 \pm(2.6)$ & $42.33 \pm(2.9)$ \\
Activity scores & $63.3 \pm(2.1)$ & $64.83 \pm(2.4)$ \\
Impact on daily living score & $52.1 \pm(3.2)$ & $47.3 \pm(3.3)$ \\
Total integrated score & $59.6 \pm(3.2)$ & $58.5 \pm(3.7)$ \\
Walking distance, $m$ & $284 \pm(18)$ & $273 \pm(19)$ \\
\hline
\end{tabular}

Notes: Data are presented as mean \pm SD. 
Table 4 SGRQ scores for control and active groups

\begin{tabular}{|c|c|c|c|c|c|c|c|c|c|c|c|c|}
\hline Group & SI & Al & II & TI & $\mathbf{S 2}$ & A2 & 12 & T2 & Dif.S & Dif.A & Dif.I & Dif.T \\
\hline \multirow[t]{3}{*}{ Control } & 42.33 & 64.83 & 47.3 & 58.5 & 39.5 & 63.66 & 46 & 57 & -2.83 & -1.2 & -1.3 & -1.5 \\
\hline & \pm & \pm & \pm & \pm & \pm & \pm & \pm & \pm & \pm & \pm & \pm & \pm \\
\hline & (2.9) & (2.4) & (3.3) & (3.7) & (2.7) & (3.3) & (4.I) & (3.0) & $(0.8)$ & $(0.3)$ & (0.9) & $(0.4)$ \\
\hline \multirow[t]{3}{*}{ Active } & 38.2 & 63.3 & 52.1 & 59.6 & 31.9 & 57.8 & 47.2 & 47.3 & -7.7 & -5.5 & -4.9 & -12.3 \\
\hline & \pm & \pm & \pm & \pm & \pm & \pm & \pm & \pm & \pm & \pm & \pm & \pm \\
\hline & (2.6) & (2.I) & (3.0) & (3.2) & (3.3) & (2.3) & (2.6) & (2.3) & (1.2) & $(0.9)$ & (0.4) & (I.4) \\
\hline
\end{tabular}

Notes: Data are presented mean \pm SD; Study Entry Score SI,AI,II,TI; I4-week Score S2,A2,I2,T2; Difference of score between study entry and after I4 weeks: Dif.S, Dif.A, Dif.I, Dif.T.

Abbreviations: S, Symptom;A, Activity; I, Impact; T, Total.

6-min mean distance at study entry, although it did not differ significantly from that of the control group. There was a mean increase of more than $54 \mathrm{~m}$ (a significant increase; Redelmeier et al 1997) in the active group after 14 weeks, which was significantly greater than the mean change in the control group $(\mathrm{p}<0.05)$. In other words, $68 \%$ of the patients in the active group presented a significant improvement in the distance of walking test at the end of 14 weeks.

\section{Pulmonary function}

There was no significant change in any of the parameters of the pulmonary function, neither within the active group nor within the control group as shown in Table 6 .

\section{BODE index}

A large decrease of two points (from 6 to 4 ) in the score of BODE index for the patients of the rehabilitation group was noted, the largest part of this decrease was due to the decrease in the dyspnoea, whereas we did not find such a decrease or any other changes in the BODE index of the patients of the control group as shown in Table 7.

\section{Discussion}

Our current study has shown that the physical exercise program which was designed with the objective of increasing the strength of the lower limb muscles by using a bicycle improves the quality of life and sub-maximal exercise capacity in patients with moderate COPD.

Table 5 Six-minute walking distances for control and active groups

\begin{tabular}{llll}
\hline Group & Study entry & | 4-week & Difference \\
\hline Control & $273 \pm(19) \mathrm{m}$ & $281 \pm(22) \mathrm{m}$ & $+8 \pm(8.6) \mathrm{m}$ \\
Active & $284 \pm(18) \mathrm{m}$ & $330 \pm(19) \mathrm{m}$ & $+46 \pm(9.2) \mathrm{m}$ \\
\hline
\end{tabular}

Notes: Data are presented as mean \pm SD.
Even though there have been significant advances in the understanding and management of COPD (Fishman et al 2005; Shapiro et al 2005), suggesting that the disease may be largely preventable, it remains only marginally treatable. This is probably because COPD is due to a slowly progressive destructive process of the lung that is poorly reversible when manifested clinically and because it has systemic effects and frequent comorbidities that should be managed more comprehensively (Boyd et al 2005).

Thus, management of patients with COPD includes education, preventive care, smoking cessation, pharmacological and oxygen therapy, and pulmonary rehabilitation (Lacasse et al 1996).

Pulmonary rehabilitation is an effective treatment option for COPD (Troosters et al 2005), may improve exercise capacity, at least in part, by reducing systemic oxidative stress (Mercken et al 2005), also exert ional dyspnoea is consistently reported to be reduced after pulmonary rehabilitation (Gigliotti et al 2003). The reduction in dyspnoea is mediated through the reduced ventilatory requirements at identical work rates and identical oxygen consumption.

The clinical relevance of the benefit of pulmonary rehabilitation is illustrated by improved functional capacity, as measured by the 6 -minute walk test. The minimal clinically important difference of the 6-minute walking test has been estimated to be $54 \mathrm{~m}$ (Redelmeier et al 1997). This test (6MWT) is used to assess the functional status of patients with COPD. Over time it has proved to be reliable, objective, inexpensive and easy to apply regardless of the patient's age and educational level (Bittner et al 1993). It has been shown to predict survival post-pulmonary rehabilitation (Gerardi et al 1996).

Thus, we found that most of our patients (within the active group) represented an increase in the distance covered in the $6 \mathrm{MWT}$ of more than $54 \mathrm{~m}$ (the minimal significant increase) at the end of the rehabilitation program; this improvement 
Table 6 Pulmonary function for control and active groups

\begin{tabular}{|c|c|c|c|c|c|c|}
\hline \multirow[t]{2}{*}{ Parameters } & \multicolumn{3}{|l|}{ Active group } & \multicolumn{3}{|c|}{ Control group } \\
\hline & Study entry & I4-week & Difference & Study entry & I4-week & Difference \\
\hline $\begin{array}{l}\text { FVC,\% } \\
\text { Predicted }\end{array}$ & $\begin{array}{l}86.1 \pm \\
(17.8)\end{array}$ & $\begin{array}{l}81.7 \pm \\
(3.5)\end{array}$ & $\begin{array}{l}-4.4 \pm \\
(9.8)\end{array}$ & $\begin{array}{l}78.7 \pm \\
(3.5)\end{array}$ & $\begin{array}{l}79.65 \pm \\
(3.3)\end{array}$ & $\begin{array}{l}+0.95 \pm \\
(1.4)\end{array}$ \\
\hline $\begin{array}{l}\mathrm{FEV}_{1}, \% \\
\text { Predicted }\end{array}$ & $\begin{array}{l}41.9 \pm \\
(2.6)\end{array}$ & $\begin{array}{l}41.3 \pm \\
(3.6)\end{array}$ & $\begin{array}{l}-0.8 \pm \\
(0.4)\end{array}$ & $\begin{array}{l}43.33 \pm \\
(3.6)\end{array}$ & $\begin{array}{l}44.83 \pm \\
(4.17)\end{array}$ & $\begin{array}{l}+1.5 \pm \\
(1.6)\end{array}$ \\
\hline $\begin{array}{l}\mathrm{RV}, \% \\
\text { Predicted }\end{array}$ & $\begin{array}{l}160.6 \pm \\
(5.6)\end{array}$ & $\begin{array}{l}163 \pm \\
(4.7)\end{array}$ & $\begin{array}{l}+2.4 \pm \\
(1.3)\end{array}$ & $\begin{array}{l}154.66 \pm \\
(3.64)\end{array}$ & $\begin{array}{l}151 \pm \\
(2.36)\end{array}$ & $\begin{array}{l}-3.66 \pm \\
(0.8)\end{array}$ \\
\hline
\end{tabular}

Notes: Data are presented as mean \pm SD.

may have been due to changes in ventilatory capacity and improved respiratory patterns.

Our study has shown also, that patients submitted the proposed protocol of rehabilitation presented a significant improvement in quality of life as assessed by the SGRQ, which was sensitive in detecting these improvements in quality of life in our patients with COPD. Nevertheless, there are several different instruments for measuring health - related quality of life in patients with COPD, of which the chronic respiratory disease questionnaire, the SGRQ, and the baseline dyspnoea index have been demonstrated to be reproducible, valid, and responsive (Curtis et al 1994). The most comprehensive disease-specific instrument, the chronic respiratory disease questionnaire (Guyatt et al 1989), deals with perceptions of dyspnoea, fatigue, patients' sense of control over their disease, and emotional dysfunction. It depends in part on each patient identifying areas of life disturbed by disease, so that the result is individualized, and is difficult to compare between different studies. The SGRQ has the advantage of being a standardized questionnaire, allowing comparison between studies and different interventions, and hence was chosen for this study. The SGRQ routinely takes about 10 min to administer, which in our study was supervised by an observer blinded to the patients' randomization. Each component of the questionnaire gives a weighted score between 0 and 100, including the total, with normal values in healthy individuals of $<7$ for each component. A change of 4 points in the total score has been shown to represent the minimally clinically significant change (Jones et al 1991; Quirk et al 1991). Thus our results, with reduction in total scores (within the active group) of 12.3 at the end of 14 weeks clearly represent clinically significant benefits from the treatment program. We can say the same thing for the other components (symptoms, activity, and impact) which gave significant reductions within the active group too. They are comparable with the changes observed by (Griffiths et al 2000). That group studied the effect of outpatient rehabilitation in patients with COPD, and observed a mean improvement in total SGRQ score of 9.4 points at 6 weeks, which remained significant at 4.8 points after one year.

Studies of standard respiratory rehabilitation programs have shown that aerobic physical conditioning does not modify lung function (American College of Chest Physicians 1997; American Thoracic Society 1999). Consequently, the fact that lung function is not altered by pulmonary rehabilitation is broadly accepted in medical literature. Kakizaki et al showed that FVC is increased by stretching respiratory muscles (Kakizaki et al 1999). The FVC of an individual is dependent on lung elastic recoil, chest wall elasticity and respiratory muscle fitness. Exercises in our study are not designed to improve respiratory muscle stretching and have no effect on lung tissue structure. Thus, it is possible

Table 7 BODE index scores

\begin{tabular}{|c|c|c|c|c|c|c|}
\hline & \multicolumn{3}{|c|}{ Active group } & \multicolumn{3}{|c|}{ Control group } \\
\hline & Baseline & I4 weeks & $\overline{\text { Difference }}$ & Baseline & I4 weeks & Difference \\
\hline FEV $(\%)$ & $2 \pm(0.3)$ & $2 \pm(0.2)$ & 0 & $2 \pm(0.42)$ & $2 \pm(0.58)$ & 0 \\
\hline $\mathrm{D} .6 \mathrm{MWT}(\mathrm{m})$ & $\mathrm{I} \pm(0.4)$ & $\mathrm{I} \pm(0.33)$ & 0 & $\mathrm{I} \pm(0.29)$ & $\mathrm{I} \pm(0.46)$ & 0 \\
\hline Dyspnoea & $2 \pm(0.6)$ & $0 \pm(0.8)$ & -2 & $2 \pm(0.7)$ & $2 \pm(0.8)$ & 0 \\
\hline $\mathrm{BMI}$ & $\mathrm{I} \pm(0.4)$ & $I \pm(0.6)$ & 0 & $I \pm(0.39)$ & $\mathrm{I} \pm(0.42)$ & 0 \\
\hline BODE index & $6 \pm(0.44)$ & $4 \pm(0.38)$ & -2 & $6 \pm(0.7)$ & $6 \pm(0.6)$ & 0 \\
\hline
\end{tabular}

Notes: Data are presented as scores (from 0 to 10); Data are presented as mean \pm SD. 
that the Kakizaki exercises modified chest wall elasticity or respiratory muscle strength.

A recent multicenter, community-based experience (California Pulmonary Rehabilitation Collaborative Group 2004) (also known as the California Collaborative) included nine centers of 647 patients, which showed consistent benefits in dyspnoea and quality of life as well as a reduction in health-care utilization (eg, physician visits, telephone calls, hospital days, and urgent care visits) over an 18-month follow-up period.

Guidelines (American College of Chest Physicians 1997; American Thoracic Society 1999) on pulmonary rehabilitation have reviewed the strength of the evidence for current practices. One analysis gave the strength of improvement in quality of life with rehabilitation as grade $\mathrm{B}$, and outlined three randomized controlled trials addressing this topic; of these, only one trial used a control group with no rehabilitation or educational input and was also outpatient-based rehabilitation (Wijkstra et al 1994). The American Thoracic Society review (American Thoracic Society 1999) did not identify any further studies of the type described in the current study, namely exclusively outpatient-based rehabilitation with a control group not receiving anything other than standard medical care. Our search in the literature revealed two articles (Engostrom et al 1999; Griffiths et al 2000) that are of this type. The regimen described by (Griffiths et al 2000) was very similar to our own, involving a 6-week outpatient-based program, and showed improvements in quality of life that were sustained for a year. Engstrom and colleagues (1999) also used an initial 6-week rehabilitation program, but they described a gradual transition from this to a home based program and also incorporated booster sessions. It is of interest that in their study, no significant effect was seen on the scored achieved with the SGRQ, although minor improvements in exercise tolerance were observed.

Finally, we used BODE index (Bartolome et al 2004) as a predictor of the risk of death from any cause, not only from respiratory causes. It is useful because it includes one domain that quantifies the degree of pulmonary impairment $\left(\mathrm{FEV}_{1}\right)$, one that captures the patients' perception of symptoms (the MMRC dyspnoea scale) which we chose because it predicts the likelihood of survival among patients with COPD (Nishimura et al 2002), and two independent domains (the distance walked in six minutes and the body mass index) that express the systemic consequences of COPD.

The present study contributes additional information to the knowledge regarding the benefits of the pulmonary rehabilitation on exercise capacity and the quality of life.
It supports previous data that an outpatient program can provide benefits to patients with COPD.

Our current study was not designed to determine whether outpatient pulmonary rehabilitation reduces exacerbations and hospital admissions in chronic obstructive pulmonary disease patients. Further studies should be performed in order to clarify these questions.

In conclusion, this study demonstrated in a controlled study that a 14-week program of outpatient-based rehabilitation of $3 \mathrm{~h} / \mathrm{wk}$ achieved a clinically significant increase in patient' quality of life, also in exercise tolerance and a decrease in the risk of death as measured using BODE index without any changes in the pulmonary function.

Thus, another program of rehabilitation might be added to the other programs, and also may represent yet another valuable tool in pulmonary rehabilitation.

\section{References}

Agusti AG. 2005. Systemic effects of chronic obstructive pulmonary disease. Proc Am Thoracic Soc, 2:367-370. Discussion 371-2.

American College of Chest Physicians (ACCP). 1997. Pulmonary Rehabilitation. Joint ACCP/AACVPR Evidence-Based Guidelines. Chest, 112:1363-96.

American Thoracic Society. 1995. Standards for the diagnosis and care of patients with chronic obstructive pulmonary disease. Am Rev Respir Crit Care Med, 152:S77-120.

American Thoracic Society, European Respiratory Society. 1999. Skeletal muscle dysfunction in chronic obstructive pulmonary disease: a statement of the American Thoracic Society and European Respiratory Society. Am J Respir Crit Care Med, 159:S1-40.

American Thoracic Society. 1999. Pulmonary Rehabilitation Guideline Panel. Am J Respir Crit Care Med, 159:1666-82.

Bartolome R, Cilli CG, Cote JM, et al. 2004. The body-mass index, airflow obstruction, dyspnea, and exercise capacity index in chronic obstructive pulmonary disease. $N$ Engl J Med, 350:1005-12.

Bittner V, Weiner DH, Yusuf S, et al. 1993. Prediction of mortality and morbidity with a 6-minute walk test in patients with left ventricular dysfunction [abstract]. JAMA, 270:1702-7.

Boyd CM, Darer J, Boult C, et al. 2005. Clinical practice guidelines and quality of care for older patients with multiple comorbid diseases: implications for pay for performance. JAMA, 294:716-24.

California Pulmonary Rehabilitation Collaborative Group. 2004. Effects of pulmonary rehabilitation of dyspnoea, quality of life, and healthcare costs in California. J Cardiopulm Rehabil, 24:52-62.

Celli BR, MacNee W. 2004. Standard for diagnosis and treatment of patients with COPD: a summary of the ATS/ERS position paper. Eur Respir $J, 23: 932-46$.

Curtis JR, Deyo RA, Hudson LD. 1994. Health-related quality of life among patients with chronic obstructive pulmonary disease. Thorax, 49:162-70.

Debigare R, Cote CH, Maltais F. 2001. Peripheral muscle wasting in chronic obstructive pulmonary disease: clinical relevance and mechanisms. Am J Respir Crit Care Med, 164:1712-17.

Decramer M, Gosselink R, Toosters T, et al. 1997. Muscle weakness is related to utilization of health care resources in COPD patients. Eur Respir J, 10:417-23.

Decramer M, Gosselink R, Toosters T, et al. 1998. Peripheral muscle force in a determinant of survival in COPD. Eur Respir J, 12:2615.

Engostrom, CP, Persson, LO, Larsson, S, et al. 1999. Long-term effects of a pulmonary rehabilitation programme in outpatients with chronic obstructive pulmonary disease: a randomized controlled study. Scand J Rehab Med, 31:207-13. 
Fabbri LM, Hurd SS. 2003. Global strategy for the diagnosis, management, and prevention of COPD: 2003 update. Eur Respir J, 22:1-2.

Fishman AP. 2005. One hundred years of chronic obstructive pulmonary disease. Am J Respir Crit Care Med, 171:941-8.

Gerardi DA, Lovett L, Benoit-Connors ML, et al. 1996. Variables related to increased mortality following outpatient pulmonary rehabilitation [abstract]. Eur Respir J, 9:431-5.

Gigliotti F, Coli C, Bianchi R, et al. 2003. Exercise training improves exertional dyspnoea in patients with COPD: evidence of the role of mechanical factors. Chest, 123:1794-802.

Global Initiative for Chronic Obstructive Lung Disease. 2005. Workshop Report, Global Strategy for Diagnosis, Management, and Prevention of COPD. Update Sept. 2005. Bethesda, MD: National Institutes of Health, National Heart, Lung and Blood Institute; 2005 [online]. Accessed on 5 October 2007. URL: http://www.goldcopd.com/.

Griffiths TL, Burr ML, Campbell IA, et al. 2000. Results at 1 year of outpatient multidisciplinary pulmonary rehabilitation: a randomized controlled trial. Lancet, 355:362-8.

Guyatt G, Townsend M, Keller J, et al. 1989. Measuring functional status in chronic lung disease: conclusions from a randomized control trial. J Respir Med, 83:293-7.

Jones PW, Quirk FH, Baveystock CM. 1991. The St. George's Respiratory Questionnaire. J Respir Med, 85(Suppl B):25-31.

Jones PW, Quirk FH, Baveystock CM, et al. 1992. A self-complete measure of health status for chronic airflow limitations: the St. George's respiratory questionnaire. Am Rev Respir Dis, 145:1321-7.

Kakizaki F, Shibuya M, Yamazaki T, et al. 1999. Preliminary report on the effects of respiratory muscle stretch gymnastics on chest wall mobility in patients with chronic obstructive pulmonary disease. Respir Care, 44:409-14.

Lacasse Y, Wong E, Guyatt GH, et al. 1996. Meta-analysis of respiratory rehabilitation in chronic obstructive pulmonary disease. Lancet, 348:1115-19.

Laghi F, Tobin MJ. 2003. Disorders of the respiratory muscles. Am J Respir Crit Care Med, 168:10-48.

MacNee W. 2005. Pulmonary and systemic oxidant /antioxidant imbalance in chronic obstructive pulmonary disease. Proc Am Thorac Soc, 2:50-60.

Man WD, Hopkinson NS, Harraf F, et al. 2005. Abdominal muscle and quadriceps strength in chronic obstructive pulmonary disease. Thorax, 60:718-22.

Marquis K, Debigare R, Lacasse Y, et al. 2002. Midthigh muscle crosssectional area is a better predictor of mortality than body mass index in patients with chronic obstructive pulmonary disease. Am J Respir Crit Care Med, 166:809-13.

Mercken EM, Hageman GJ, Schols AM, et al. 2005. Rehabilitation decreases exercise-induced oxidative stress in chronic obstructive pulmonary disease. Am J Respir Crit Care Med, 172:994-1001.

Nishimura K, Izumi T, Tsukino M, et al. 2002. Dyspnea is a better predictor of 5-year survival than airway obstruction in patients with COPD. Chest, 121:1434-40.
Ottenheijm CA, Heunks LM, Sieck GC, et al. 2005. Diaphragm dysfunction in chronic obstructive pulmonary disease. Am J Respir Crit Care Med, 172:200-5.

Oudijk EJ, Nijhuis EH, Zwank MD, et al. 2005. Systemic inflammation in COPD visualised by gene profiling in peripheral blood neutriphils. Thorax, 60:538-44.

Pitta F, Toosters T, Spruit MA, et al. 2005. Characteristics of physical activities in daily life in chronic obstructive pulmonary disease. Am J Respir Crit Care Med, 171:972-7.

Quirk FH, Baveystock CM, Wilson RC, et al. 1991. Influence of demographic and disease related factors on the degree of distress associated with symptoms and restrictions on the daily living due to asthma in six countries. Eur Respir Dis, 4:167-71.

Redelmeier DA, Bayoumi AM, Goldstein RS, et al. 1997. Interpreting small differences in functional status: The six minute walk test in chronic lung disease patients [abstract]. Am J Respir Crit Care Med, 155:1278-82.

Rennard SI, Calverley P. 2003. Rescue. Therapy and paradox of the Barcalounger. Eur Respir J, 21:916-17.

Ries AL, Kaplan RM, Limberg TM, et al. 1995. Effects of pulmonary rehabilitation on physiologic and psychosocial outcomes in patients with chronic obstructive pulmonary disease. Ann Intern Med, 122:823-32.

Shapiro SD, Ingenito EP. 2005. The pathogenesis of chronic obstructive pulmonary disease: advances in the past 100 years. Am J Respir Cell Mol Biol, 32:367-72.

Sin DD, Lacy P, York E, et al. 2004. Effects of fluticasone on systemic markers of inflammation in chronic obstructive pulmonary disease. Am J Respir Crit Care Med, 170:760-5.

Strong K, Mathers C, Leeder S, et al. 2005. Preventing chronic diseases: how many lives can we save? Lancet, 366:1578-82.

Tapson VF. 2005. The role of smoking in coagulation and thromboembolism in chronic obstructive pulmonary disease. Proc Am Thorac Soc, 2:71-7.

Troosters T, Casaburi R, Gosselink R, et al. 2005. Pulmonary rehabilitation in chronic obstructive pulmonary disease. Am J Respir Crit Care Med, 172:19-38.

Verrill D, Borton C, Beasley W, et al. 2005. The effects of short-term and long term pulmonary rehabilitation on functional capacity, perceived dyspnoea, and quality of life. Chest, 128:673-83.

Wijkstra PJ, Van Altena R, Kraan J, et al. 1994. Quality of life in patients with chronic obstructive pulmonary disease improves after rehabilitation at home. Eur Respir J, 7:269-73.

Wouters EF. 2005. Local and systemic inflammation in chronic obstructive pulmonary disease. Proc Am Thorac Soc, 2:26-33.

Yasuda H, Yamaya M, Nakayama K, et al. 2005. Increased arterial carboxyhemoglobin concentrations in chronic obstructive pulmonary disease. Am J Respir Crit Care Med, 171:1246-51. 